\title{
Motivation in mechanics of materials classes: An experimental approach
}

Article in International Journal of Mechanical Engineering Education · June 2017

DOI: $10.1177 / 0306419017708643$

CITATIONS

0

3 authors, including:

\section{Hugo Silva}

University of Minho

6 PUBLICATIONS 1 CITATION

SEE PROFILE
READS

11

Some of the authors of this publication are also working on these related projects:

Mechanical Engineering PhD View project 
Motivation in mechanics of materials classes: An

\title{
Hugo Miguel Andrade Lopes Figueiredo da Silva', Manuel João Costa ${ }^{2}$ and José Filipe Bizarro de Meireles'
}

\begin{abstract}
This work presents a novel didactic methodology for the approximation of the students to the subject of Mechanics of Materials, with the aim of improving the understanding of the inertia moment, and its relevance on the mechanical behaviour of structures. The students have grouped on groups of two to three persons. The work consisted in designing the most efficient beam having in mind several design constraints. Tensile tests were performed to determine the relevant material properties. Those were used for the analytic dimensioning of the beams. The aim of the work is to obtain the highest efficiency possible, since it results in the best mark, as possible. The efficiency was measured by the maximum load on experimental bending testing, divided by the mass of the beam. The results, as well as the interest of the methodology are discussed. It is proved that this methodology can be useful for the students to apply theoretical concepts and, at the same time, to give a deeper understanding of real experimental tests.
\end{abstract}

\section{Keywords}

Experimental Mechanics of solids, motivation induced by experimental mechanics of solids, mechanics of solids

\section{Introduction}

Students often demonstrate difficulties in understanding the behaviour of structures under mechanical loads. Some difficulties may originate from insufficient awareness of the importance of inertia moment. The students involved in the work presented a

\footnotetext{
'Department of Mechanical Engineering, University of Minho, Portugal

${ }^{2}$ School of Health Sciences, University of Minho, Portugal

\section{Corresponding author:}

Hugo Miguel Andrade Lopes Figueiredo da Silva, Department of Mechanical Engineering, University of Minho, Campus of Azurém, 4800-058 Guimarães, Portugal.

Email: hugolopessilva@gmail.com
} 
weak interest in the subject and results below the expectable. Therefore, one aim of the work is to improve their performance. An adequate mastering of this property could facilitate their understanding of how to improve structure's mechanical behaviour and create stiff and economical solutions. The mastering of the inertia moment requires knowing how to apply the theoretical concepts to real life/ professional problems.

The adoption of educational paradigms which focus on student learning and step away from teaching and instruction achieve better student learning. ${ }^{1}$ In college mechanics of materials courses, traditional teaching combines lectures - in which faculty present content to students - and exercise sessions, in which faculty select and facilitate the solving of exercises, often selected from Mechanics of Materials textbooks. Alternative learning paradigms have been introduced to promote learning in many disciplines, for example Problem Based Learning in medicine. ${ }^{2}$ In engineering education, 'Active learning' paradigms have been introduced for quite some time with positive impact on learning. ${ }^{3,4}$ Education according to active learning ${ }^{3,4}$ demands that students participate in the process of learning in the classroom, by any form of engagement, from quick exercises such as think pair share. $^{3,4}$

One strategy used with the expectation of increasing the assimilation of key concepts and the capacity of identifying the key aspects in practice is the engagement with experimentation with structure design to develop better structures. ${ }^{5}$ Very few methodologies were found in the literature about the application of experiments in mechanics of materials related fields. ${ }^{5-7}$

The work ${ }^{6}$ is about the 'geometrical project of a bridge on the teaching of technical drawing', and consisted of a project ending up in a contest, in which the resistance, the geometrical precision and lightness of a miniature bridge were evaluated. The work was followed during some lessons to evaluate the student's progress. The final grade of the project considers the project documentation $(40 \%)$, contest evaluation $(30 \%)$, originality $(20 \%)$ and the average of the project grades obtained by the entire class $(10 \%)$ [Appendix 1]. The authors considered that 'The motivation and the awareness of the importance of the Technical Drawing topics and the Resistance of Materials were clearly observed. The didactic impact of the project on the subject and on the course was, therefore, extremely positive', citation translated from Cheng et al. ${ }^{6}$ The difference of the present work when compared to Cheng et al. ${ }^{6}$ is that the scientific fields were not the same, and therefore, the didactic materials and also the evaluation criteria were also different. In the work 'Structural Mechanics: A didactic experimental set-up and its virtual tool, ${ }^{8}$ a didactic test frame was developed with the aim of calculating the reactions in isostatic and simple hyperstatic structures, as well as the measurement of flexural displacements and the determination of influence lines in beams. The virtual and real tool developed by the authors, can be used for nearly all individual learning styles, being appealing to such as: '...the sensing, the intuitive, the visual, the verbal, the active, the reflective, the sequential and the global learners' (cited from Felder ${ }^{7}$ in Marques et al. ${ }^{8}$ ). The work use the application 'SoftBeam', with 
the aim of facilitating the integration of knowledge with the practical perceptions: '... seeing is believing...' (cited from Felder ${ }^{7}$ in Marques et al. ${ }^{8}$ ), to search for meanings, to reproduce the experiments, to stimulate the attention to the details, as well as cooperation between the colleagues, to learn in a sequence, and to '... synthetize knowledge...' (cited from Felder ${ }^{7}$ in Marques et al. ${ }^{8}$ ). A substantial difference of this work in terms of didactical aspects when compared to Marques et $a l^{8}$ is that a contest was made to improve the motivation of the students, as the lack of motivation seemed to be one of the problems of the students in the course. In the work, ${ }^{9}$ didactic models are used for the teaching of practical lessons on the solid mechanics field. The methodology used in organized in three levels: On the first, the student gets in contact with the didactic model. On the second, the students are engaged on activities that involve creating, projecting, building and the analysis of the didactic models. On the advanced level, the students have to do experimental work using the physical models already developed. According to the Haguenauer, ${ }^{9}$ the implemented laboratory activities have a very positive effect in terms of learning and satisfaction by the students as well as on the use of the didactic material developed. The innovation of this methodology in relation to Haguenauer ${ }^{9}$ is that all the didactic methodology is condensed in one step. This may lead to shorter time learning, and easier understanding of what is expected from the students by them.

The approach presented in this work is underpinned by active learning exercises and requires students to evaluate the relevant factors, propitiating a deeper interpretation of its effect, particularly the inertia moment. Participation in the design, performance and interpretation of experiments requires the active engagement of students. In this work, the learning outcomes are quantified by a methodology that is presented.

\section{An overview of the rationale of the experiment}

This project was introduced as part of the requirements of the subject 'Mechanics of Materials II', on Materials Engineering BSc. Course at the University of Minho, Portugal. The students grouped in teams of two to three students. One group has only one student. The groups were self-formed by the students. The work was accompanied by a Materials Engineer, which saw the work and signed a form if the work fulfilled the requirements of the stage. This experimental work was designed considering the main principle of the Bologna process: pro-activity by the students. The students are expected to research, think and implement the solution to this problem independently, as possible.

\section{Materials and imposed constraints}

The students built beams of paper pressboard. In order to ensure the same conditions for all students, the following constraints were imposed:

1. Geometry: Beam 


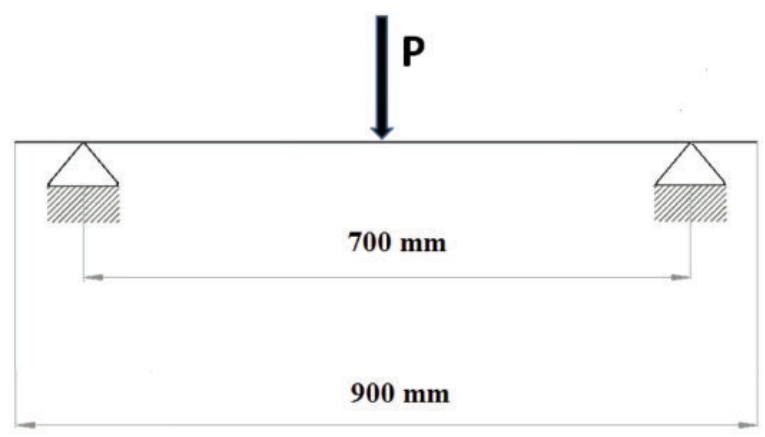

Figure I. Representation of the loading mode, along with distance between the supports and length of the beam.

2. Length: $900 \mathrm{~mm}$

3. Constant section with involving perimeter of $400 \mathrm{~mm}$

4. Material: Paper pressboard having a thickness of $3 \mathrm{~mm}$

5. Glue: Universal fluid glue-UHU, article $n^{\circ} 42875$

The materials referred in the points 4 and 5 are available inside the University campus. Those exact materials had to be used, since they have a great influence on the results. The loading mode of the beam is shown in Figure 1.

There is the freedom of selecting any section shape for the beam, however, for effects of simplification, solutions of beams with constant section along their length are recommended. It shall be given priority to the study of beams with geometries simple enough, in order to facilitate its analytic dimensioning. The solution efficiency will be evaluated by the relation (1)

$$
E_{f}=\frac{P}{m}
$$

where $P$ is the load in $\mathrm{N}$ applied in the centre of the beam in simple supported at its ends, with supports located at $700 \mathrm{~mm}$ between them, and $m$ is the weight of the beam, obtained by experimental measured of the specimen produced, before the experimental testing, by a precision scale. The maximum displacement for each beam is of $20 \mathrm{~mm}$, by application of the load $P$ on the centre of the top face of each beam. Each group has to calculate their beam analytically and indicate what is the expected value of the load to attain a deflection of $20 \mathrm{~mm}$. The groups must also dimension their beams to resistance (stresses). The formulae used to calculate the maximum load analytically is (2):

$$
P=\frac{48 E I y}{L^{3}}
$$




\section{Suggested tasks}

Each working group was informed about the conditions of execution of the work by means of general execution guidelines before the beginning of the work. The suggested tasks are listed next:

1. Gathering of the material in the campus: paper pressboard sheets and glue.

2. Suggestion of the best solution, having in mind that concentrated transverse loads will be applied in the top surface of the beam. It is highly recommended that all choices are based on theoretical fundaments.

3. Tensile testing in order to determine Young's modulus to use for the analytical dimensioning

4. Analytical dimensioning of the solution

5. Building of the pressboard models. The models must accomplish the constraints defined previously.

6. The models will be experimentally tested in the Laboratory of Mechanical testing at the University of Minho.

The experimental parameter measured was the load capacity, until the transversal displacement of $20 \mathrm{~mm}$ is attained. The minimum passing grade is ensured by attaining a transversal displacement of $20 \mathrm{~mm}$ without any type of mechanical failure, as shown in Figure 2.

From a technical point of view, it is important for the students to learn the importance of the geometry and its influence on the results. The imposed displacement of $20 \mathrm{~mm}$ makes necessary an evaluation in terms of resistance, because it is needed that the beams do not collapse before the value of displacement is met. In order to prove the efficiency of the solution, it shall be taken pictures during the application of the load, where it is possible to see the experimental setup. Also, the mass was written on each beam before the test. As such, each group must take a picture where it is possible to see the weight of the beam.

\section{Grade evaluation criterion}

Efficiency. All solutions which fulfilled the specified aims achieved the minimum mark of 11 values out of 20. The marking criteria to mark the efficiency of the

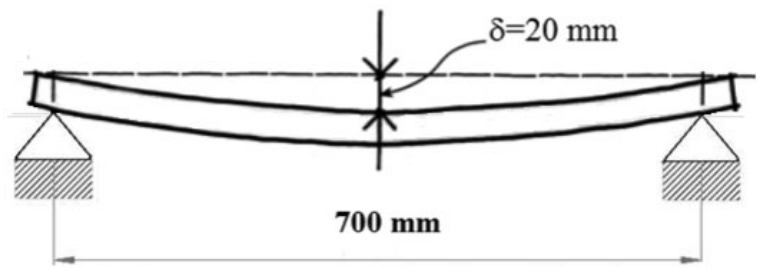

Figure 2. Deflection value to be considered. ${ }^{10}$ 
Table I. Calculated mark using (3).

\begin{tabular}{llc}
\hline$n$ & Mark & Efficiency \\
\hline 9 & 20 & 1287.3 \\
8 & 19 & 1178.2 \\
7 & 18 & 1069.1 \\
6 & 17 & 960.0 \\
5 & 16 & 850.9 \\
4 & 15 & 741.9 \\
3 & 14 & 632.8 \\
2 & 13 & 523.7 \\
1 & 12 & 414.6 \\
0 & 11 & 305.5 \\
\hline
\end{tabular}

beams built by the students, in a scale from 11 to 20 used the efficiency obtained in the bending test, according to equation 3 :

$$
\text { Efficiency }=E f_{\min }+n_{i} * \frac{\left(E f_{\max }-E f_{\min }\right)}{n}
$$

where $E f_{\min }$ is the lowest efficiency obtained in bending test (Table 1), $E f_{\max }$ is the highest efficiency obtained in bending test (Table 1), $n$ is the number of intervals to be considered and $n_{i}$ is a number between 0 and $n$.

There are no marks below 11 because all groups could do the test and deliver a report with acceptable quality. According to equation (2), Table 1 can be written.

A mark of 20 was assigned to the student with highest efficiency. Then, the student with efficiency between the maximum and that for $n=8$ was marked with 19 , and so on until a mark of 11 . A mark of 11 will be given to the lowest efficiency, and to those having an efficiency between the values presented for $\mathrm{n}=0$ and $\mathrm{n}=1$. Therefore, Table 1 can be rewritten as shown in Table 2.

The highest the Ef, the better the mark is in the experimental part of the work, and the more efficient is the solution.

Report evaluation. The Final Report is evaluated using the following criteria (Table 3).

The aim is to create a formulation that allows the clarification of the differences in quality between the works, considering both the conception, building of the prototype and the experimental results obtained. The report is essential to evaluate these aspects of the work in detail.

\section{Experimental testing}

In order to perform the experimental test, the students needed to determine the Young's Modulus of the material previously. Because of this, the experimental tests 
Table 2. Efficiency intervals used to calculate the student's mark.

\begin{tabular}{lll}
\hline $\mathrm{n}$ & Mark & Efficiency \\
\hline 9 & 20 & 1287 \\
8 & 19 & $(1178 ; 1287)$ \\
7 & 18 & $(1069 ; 1178)$ \\
6 & 17 & $(960 ; 1069)$ \\
5 & 16 & $(851 ; 960)$ \\
4 & 15 & $(742 ; 851)$ \\
3 & 14 & $(633 ; 742)$ \\
2 & 13 & $(524 ; 633)$ \\
1 & 12 & $(415 ; 524)$ \\
0 & 11 & $(306 ; 415)$ \\
\hline
\end{tabular}

Table 3. Weight of the several parts of the work on the final mark of the written report.

\begin{tabular}{ll}
\hline Subject & Points \\
\hline Theoretical fundaments & 10 \\
Global report presentation & 15 \\
Technical drawings & 10 \\
Solution efficiency (determined by experimental testing) & 40 \\
Analytical dimensioning of the problem & 25 \\
Total & 100 \\
\hline
\end{tabular}

started with a tensile test, for the determination of the Young's Modulus, and then the bending test.

\section{Tensile test}

In order to be possible the comparison between the obtained results using the theory with the experimental results obtained in the experimental bending test, a characterization was done to the tested material (paper pressboard) by means of a tensile test. The characterization was done by the students, who prepared the specimens and then tested them with the help of the laboratory technician on a tensile test device. The aim of the characterization was to obtain the Young's Modulus of the material used to make the experimental specimens. Figure 3 shows the specimen coupled with the machine during the tensile test.

The Young's Modulus obtained was approximately equal to $0.5 \mathrm{GPa}$. This value was obtained by three experimental tests on which every student was involved. 


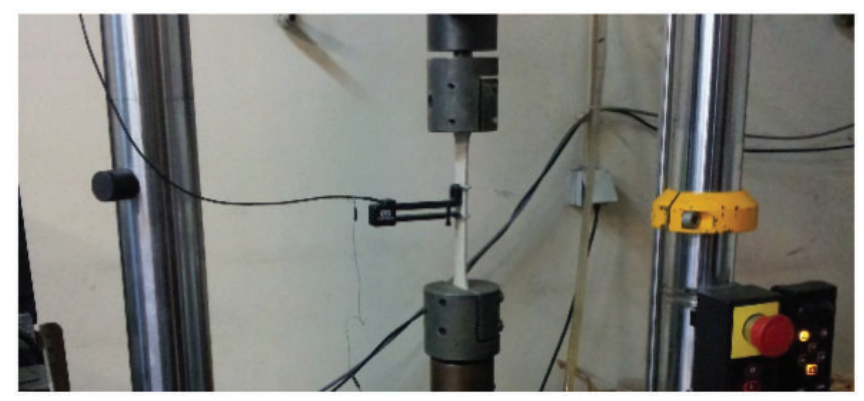

Figure 3. Specimen coupled with the tensile testing machine.

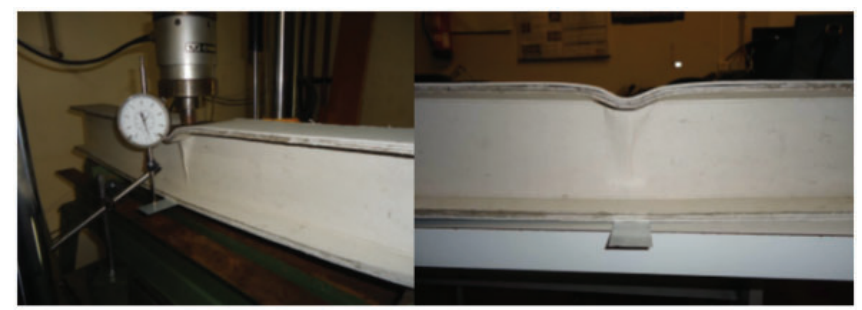

Figure 4. A beam: during the test (left) and after the test (right).

\section{Bending test}

The bending test was the method used to evaluate the efficiency of the beams built by the students. The number of evaluated students was 37 , in a total of 14 groups. The bending test was performed after the models are built. The bending force was applied by an Instron 8874 tensile/compression testing machine, reproducing the situation described in Figure 1. First, the beam was placed between the two simple supports, with a distance between them of $700 \mathrm{~mm}$. The beam, having a length of $900 \mathrm{~mm}$ was centred on the supports. A dial indicator was used to measure the displacement of the beam on the centre of the lower face (Figure 4). In order for this to be possible, a steel plate was glued to each beam before the test. The device was calibrated in order to compensate the initial displacement when placed on the measuring place. The measuring error of the device is $\pm 0.005 \mathrm{~mm}$. The load was applied with a speed of $0.08 \mathrm{~mm} / \mathrm{s}$. The maximum load was used for the calculation of the efficiency, but all beams had to reach $20 \mathrm{~mm}$ of displacement in order to have a passing grade. After the $20 \mathrm{~mm}$ of displacement, the test was stopped and the load removed. As the load was removed, there was a partial recovery of the deformation, known as resilience. Figure 4 shows a beam during the test, along with the measuring device and load cell. 
Table 4. Perimeter and the length of the beams.

\begin{tabular}{cclll}
\hline Group & Time & shape & Perimeter $(\mathrm{m})$ & Length $(\mathrm{m})$ \\
\hline 1 & $09: 00$ & RHS & 0.28 & 0.9 \\
2 & $09: 20$ & I-shape & 0.4 & 0.9 \\
3 & $09: 40$ & I-shape & 0.4 & 0.9 \\
4 & $14: 40$ & I-shape & 0.399 & 0.9 \\
5 & $00: 00$ & I-shape & 0.4 & 0.9 \\
6 & $13: 20$ & I-shape & 0.4 & 0.9 \\
7 & $13: 40$ & RHS & 0.4 & 0.9 \\
8 & $14: 00$ & I-shape & 0.338 & 0.9 \\
9 & $10: 20$ & I-shape & 0.4 & 0.9 \\
11 & $14: 20$ & I-shape & 0.398 & 0.9 \\
12 & $10: 40$ & I-shape & 0.383 & 0.7 \\
13 & $11: 00$ & I-shape & 0.4 & 0.9 \\
14 & $11: 20$ & I-shape & 0.4 & 0.7 \\
15 & $15: 00$ & I-shape & 0.354 & 0.9 \\
\hline
\end{tabular}

Two types of beams were chosen by the students: most are I-shaped beams, but also rectangular section hollow-box beams (RHS). Those were all tested on bending test.

The type of test is three-point bending. In three-point bending, it is expected to obtain a much more localized deformation in the point of load application, with less stress and deflection distribution to the rest of the beam when compared with other bending tests using more points: i.e. four-point bending. In four-point bending, as the loads are better distributed, it would be expected a higher load capacity of all structures due to a lower local deformation.

Table 4 shows the perimeter and the length of the beams, as measured one by one with a ruler.

Some students did built beams with $0.7 \mathrm{~m}$ of length. In those beams, the supports were kept at the same distance between them as in any other test. The beams built by the students are shown in Figure 5.

It is possible to see that the majority of the groups built I-shaped profiles, and only few built RHS (Rectangular hollow sections), which is the expected, because the I-shaped beam presents a higher moment of resistance in comparative terms.

\section{Results}

The expected results had to show clearly which solutions are the most efficient. Therefore, the formula 3 was used for the calculation of the efficiency and the mark obtained in the bending test. 


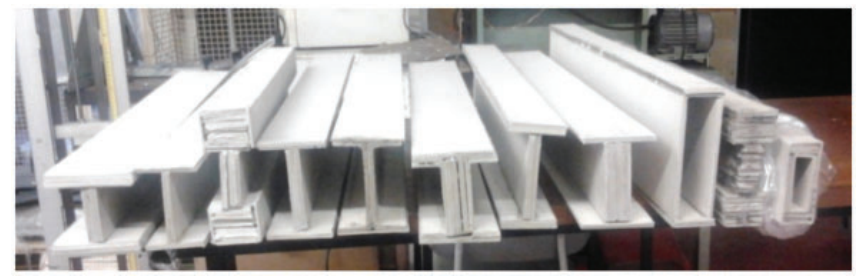

Figure 5. Some beams built by the students for the experimental test (cont.).

Table 5. Efficiency obtained in each experimental test and the corresponding mark.

\begin{tabular}{cllll}
\hline Group & Maximum load $(\mathrm{N})$ & Mass $(\mathrm{kg})$ & Ef $(\mathrm{N} / \mathrm{kg})$ & Mark \\
\hline 1 & 1755.2 & 1.6 & 1066.3 & 17 \\
2 & 2364.6 & 1.9 & 1233.6 & 19 \\
3 & 4196.6 & 3.3 & 1253.3 & 19 \\
4 & 2429.1 & 2.2 & 1128.0 & 18 \\
5 & 2336.2 & 2.0 & 1105.5 & 18 \\
6 & 4154.9 & 2.9 & 1287.3 & 20 \\
7 & 1262.8 & 1.8 & 473.9 & 12 \\
8 & 1237.9 & 1.1 & 1116.9 & 18 \\
9 & 2777.5 & 2.3 & 1151.8 & 18 \\
11 & 2667.5 & 3.0 & 900.4 & 16 \\
12 & 2453.9 & 3.9 & 626.2 & 13 \\
13 & 2185.0 & 5.0 & 440.3 & 12 \\
14 & 1874.6 & 4.2 & 305.5 & 11 \\
15 & 1267.9 & 2.0 & 641.2 & 14 \\
\hline
\end{tabular}

\section{Grades obtained}

Grades on bending test. The resulting mark for each group was calculated using the intervals that result in the application of equation (3). The mark was measured by the efficiency, and the efficiency was calculated by the ratio of the load capacity, i.e. the maximum load during the test, divided by the mass of the specimen. Table 5 shows the maximum load, the mass and the corresponding efficiency for each experimental test. The efficiency $E f$ is given by the ratio between the load and the mass and the mark is given according to the intervals of Table 2.

Final grades. The final mark has in account the weight of $60 \%$ regarding the report and $40 \%$ regarding the efficiency obtained in the experimental test. Figure 6 shows the final marks by group. Figure 7 shows the final mark, also by group. 


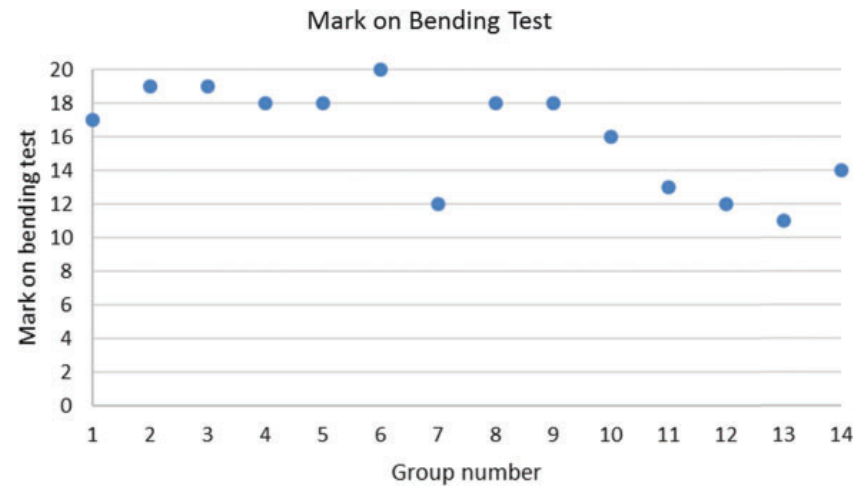

Figure 6. Final marks by group.

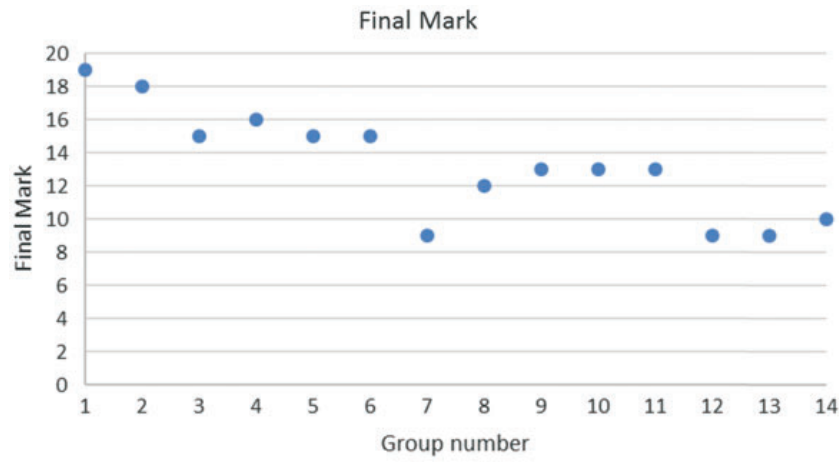

Figure 7. Final mark by group.

Apart from the experimental test, which is worth $40 \%$ of the mark, a report was done by each group and is worth $60 \%$ of the final mark. The minimum admissible final mark in the work was 8 in a scale from 0 to 20 . Every group has successfully completed the work. The overall marks are quite reasonable, especially for secondyear students.

\section{Efficiency of the proposed methodology}

In order to assess the efficiency of the methodology, the grades of the students on the written tests before the experimental work (first exam) and after (second exam) are compared. The matters evaluated on the first and second exam are different, though both are much related to each other and also to this work. The improvement is defined as the grade on the second exam minus the grade on the first exam 
- Before experimental work

nafter experimental work

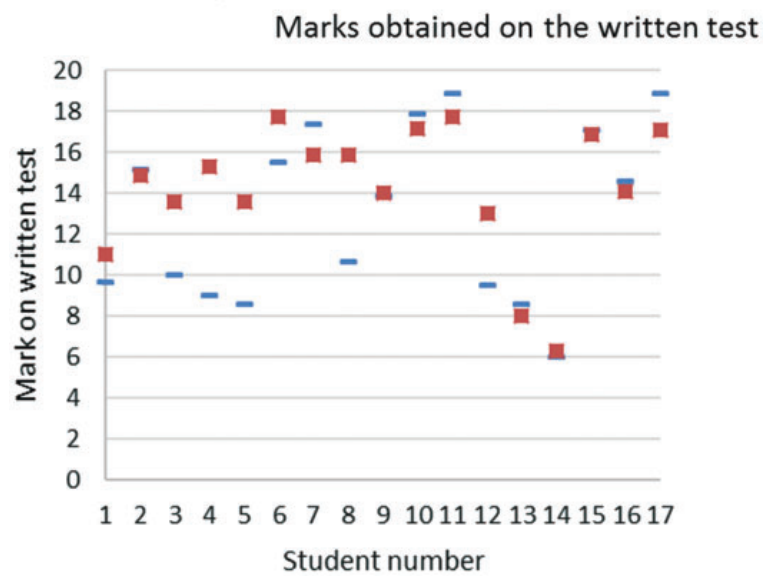

Figure 8. Grades obtained in the exams before and after the experimental work.

for every student. In order to preserve the real identity of the students, a number is presented for each, instead of their real names. Some students did the experimental test but did not do the written tests. Therefore, the number of the students presented is lower than the expected by looking at Table 5.The values are presented on a 0 to 20 scale, with a minimum passing grade of 10 , according to the Portuguese Education System. The data are shown in Figure 8.

Figure 9 shows the improvement in the mark calculated using the marks obtained before and after the experimental test for each group. Table 6 shows the average grades on the first and second exams, and the overall improvement on the marks of the students.

The fact that the first and second written exams of the subject are of different matters, although related, and the second exam is more difficult than the first, helps to validate the efficiency of the methodology in didactical terms.

\section{Discussion of results}

\section{Didactic methodology}

The student's work consisted in designing the most efficient beam having in mind several design constraints. It is proved that this novel methodology can be useful for the students to apply theoretical concepts and at the same time, to give a deeper understanding of real experimental tests. The students had the opportunity to work with several variables in order to approximate their theoretical concepts to a real 


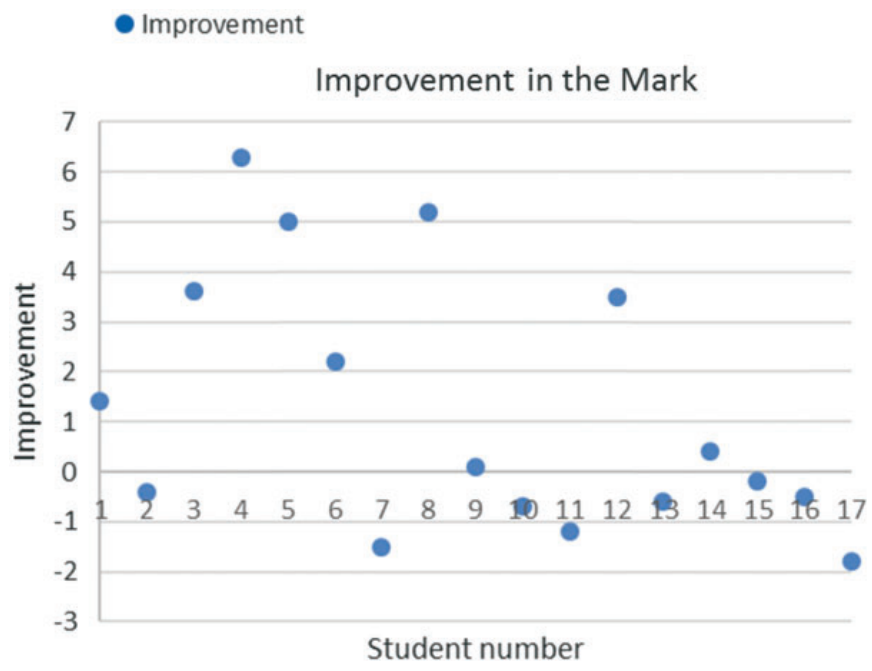

Figure 9. Improvement in the mark obtained in the written test.

Table 6. Average grades and improvement obtained in the exams before (first exam) and after the experimental work (second exam).

\begin{tabular}{llll}
\hline & First exam (0 to 20$)$ & Second exam (0 to 20) & Improvement (\%) \\
\hline Average & 13.016 & 14.246 & 9.4 \\
\hline
\end{tabular}

practical situation, and, on the other hand, to explore the intuition after the theoretical approach to the subject.

This novel didactic methodology for the teaching of mechanics of materials can be useful due to:

- This work allowed the students to integrate several valences about the subject, namely, normal and shear stresses, deformations and displacements.

- The stimulus of developing reasoning to reach the best solution, not a completely 'free' solution, but with several constraints, as constraints are present on every mechanics of materials situation, such as space constraints due to other structural members, or the type of supports.

- The learning about the importance of several aspects, such as the influence of the aspects related to the construction of the beam may be important for the education the subject. 


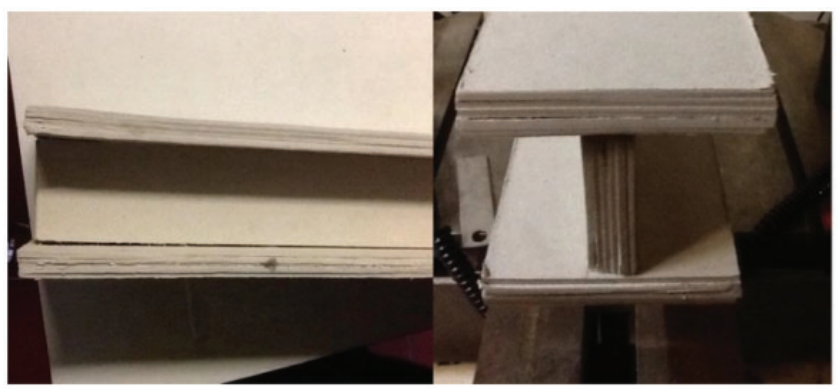

Figure 10. Relative displacement on a beam after bending test.

- The contact with the tensile and bending tests, both in terms of experimental procedure, the shaping of the results and the understanding of the importance of specific results.

On those tests, and having as basis the matter of the theoretical lessons, the students are expected to acquire knowledge and apply that knowledge on the explanation of the mechanical tests performed: both in tensile test and bending test.

With this work, it is expected that the students:

- Understand the importance of the inertia moment in structural design

- Learn how to calculate displacements and reactions on the supports on beams subjected to bending loads

- Learn how to analyse and interpret data of tensile test and bending test

- Acquire competences at the level of literature research, independent thinking, teamwork and application of theoretical concepts, being the concept of inertia moment the most important.

\section{Relative displacement phenomenon}

During the bending test, the 'flanges' had a relative displacement with the 'web' on the longitudinal direction. This phenomenon that happened on the bending test is due to the presence of shear stresses. The shear stresses have a sharp transition on the edges between the 'web' and the 'flanges', and due to that fact, the 'web' does not move during the test, but the 'flange' move. This can be seen in Figure 10.

This phenomenon happens due to:

- The fragility of the edges, both due to glue bonding and sharp shear stress increase

- The highest normal stress occurs on the extremities, i.e. on the flanges.

- The top flange may be more affected than the lower one, due to much closer application of the load. ${ }^{11}$ 


\section{Conclusions}

The following conclusions can be drawn from this work:

- The presented approach is proven to stimulate motivation in a subject that is traditionally very theoretical, and, therefore, not very interesting for most students. By participating in every stage of a real engineering project, building their own beams and watching the mechanical test, the students are now aware of the usefulness of the subject on practical applications, and, at the same time, are given a practical approach instead of theoretical only, which is considered by some, if not the most students as boring.

- A new formulation was proposed for a better evaluation of the quality of the results in order to approximate the final marks to the learning results, having in mind the quality of the results obtained experimentally and its transfer to a grading scale.

- The physical reality is different from the projected and the technique of execution has a great influence on the results. The gluing area is an important factor regarding this matter. The larger is the gluing area, the better is the behaviour of the structure, and the better is the technique of execution.

- The used materials: paper pressboard and glue made possible to create physical models which are economic and facilitates the recursive use of several models until the best solution is built.

- It was demonstrated that the way that the problem was presented to the students influenced the diversity of the proposed solutions and it was possible to observe its effect on the final response obtained, helping the perception of the involving phenomena.

- The methodology is proved to be effective due to the improvement of the grades obtained in the second written test in relation to the first, but also because the grades obtained in the experimental work were quite high in general terms. The difference between the success of some students in relation to those who did not succeed so well may be due to the interest in the subject, the curiosity in exploring the project, and the previous Engineering knowledge.

- Having in mind that the second written test of the subject is substantially more difficult than the first, an average improvement of $9.4 \%$ shows that the methodology is efficient in some degree in motivating students for the learning of the subject, as well as in improving the knowledge on the subject of Mechanics of Materials.

- The proposed methodology may also be useful for the students to further learn theoretical concepts, and apply them in practice, as well as to increase the capacity of the students to research, think and implement an engineering project. All of this strengthens the student's background and is surely beneficial for the education of every engineer in the field.

- The methodology may be interesting for application on a broad number of schools of the specialty, due to the reasons already presented. 


\section{Declaration of conflicting interests}

The author(s) declared no potential conflicts of interest with respect to the research, authorship, and/or publication of this article.

\section{Funding}

The author(s) received no financial support for the research, authorship, and/or publication of this article.

\section{References}

1. Bransford JD, Brown AL and Cocking RR (eds) How people learn: Brain, mind, experience and school. Washington, DC: National Academy Press, 2000, pp.13-25.

2. Jakobsen A and Pedersen SA. Didactic analysis of subjects in engineering education. Eur J Eng Educ 1980; 4: 1.

3. Norman GR and Schmidt HG. Effectiveness of problem-based learning curricula: Theory, practice and paper darts. Med Educ 2000; 34: 721-728.

4. Crouch C and Mazur E. Peer instruction: Ten years of experience and results. Am J Phys 2001; 69: 970-977.

5. Felder RM and Brent R. Active learning: An introduction. ASQ High Educ Brief 2009; 2; reviewed in Prince to more systematic process such as Helle L, Tynjälä $\mathrm{P}$ and Olkinuora E. Project-based learning in post-secondary education-theory, practice and rubber slings shots. High Ed 2006; 51: 287-314.

6. Cheng LY, Petreche JRD, Santos ET, et al. Projeto geométrico de uma ponte no ensino do desenho técnico. In: Proceedings of the XXVIth Brazilian congress on engineering education - COBENGE 98 (in CD-ROM), 1998. Sào Paulo: Associação Brasileira de Ensino de Engenharia.

7. Felder RM. Learning styles, www.ncsu.edu/felder-public/Learning_Styles.html (2017, accessed 9 May 2017).

8. Marques JC, Restivo MT, Sousa AA, et al. Structural mechanics: a didactic experimental set-up and its virtual tool. In: International conference on emerging e-learning technologies and applications, The High Tatras, Slovakia, 11-13 September 2008.

9. Haguenauer C. Praticas de Laboratório para ensino de resistência dos materiais e comportamento de estruturas. In: IV meeting of engineering teaching, ItaipavaPetrópolis - RJ, 24 a 27 de novembro de 1998.

10. LeCrane Chronicle. How much can i pick up with my crane? http://overheadmaterialhandlingregulation.blogspot.pt/2011/12/how-much-can-i-pick-up-with-my-crane.html (2011, accessed 9 May 2017).

11. Branco CAG and de Mecânica M. dos materiais. $5^{\mathrm{a}}$ ed. Portugal: Calouste Gulbenkian Foundation, 2011. 


\section{Appendix I: Criterion used to evaluate the subject report}

Criterion for the evaluation of the reports: Theoretical fundaments

Table 7. Criterion for the evaluation of the report: Theoretical fundaments.

\begin{tabular}{|c|c|c|c|c|}
\hline Criterion & Criterion (level 2) & Criterion (level 3) & & \\
\hline $\mathrm{a}$ & $\begin{array}{l}\text { Theoretical } \\
\text { fundaments }\end{array}$ & $10 \%$ & & \\
\hline \multirow[t]{5}{*}{ al } & Material & $30 \%$ & & \\
\hline & all & Manufacturing method & $50 \%$ & \\
\hline & $\mathrm{a} \mid 2$ & Chemical composition & $20 \%$ & \\
\hline & al3 & Microstructure & $15 \%$ & \\
\hline & al4 & Properties & $15 \%$ & \\
\hline \multirow[t]{10}{*}{$\mathrm{a} 2$} & $\begin{array}{l}\text { Beams subjected } \\
\text { to bending loads }\end{array}$ & $40 \%$ & & \\
\hline & a2I & $\begin{array}{l}\text { Fundaments about the } \\
\text { efficiency of geometries }\end{array}$ & $50 \%$ & \\
\hline & & a211 & $\begin{array}{l}\text { Importance of the } \\
\text { resistance modu- } \\
\text { lus } W\end{array}$ & $25 \%$ \\
\hline & & a212 & $\begin{array}{l}\text { Importance of the } \\
\text { inertia moment I }\end{array}$ & $30 \%$ \\
\hline & & $a 213$ & $\begin{array}{l}\text { Stress distribution } \\
\text { and fundaments } \\
\text { about stress as } \\
\text { justification for } \\
\text { the selected } \\
\text { geometry }\end{array}$ & $20 \%$ \\
\hline & & a214 & $\begin{array}{l}\text { Best beams for } \\
\text { bending (Ashby) } \\
\text { with illustration }\end{array}$ & $25 \%$ \\
\hline & $a 22$ & $\begin{array}{l}\text { Equations of the inertia } \\
\text { moment for the chosen } \\
\text { geometries }\end{array}$ & $30 \%$ & \\
\hline & & a221 & Stresses & $30 \%$ \\
\hline & & a222 & Displacements & $30 \%$ \\
\hline & & a223 & Inertia moment & $40 \%$ \\
\hline
\end{tabular}


Table 7. Continued

\begin{tabular}{llll}
\hline Criterion & Criterion (level 2) & Criterion (level 3) & \\
\hline a3 & a23 & Bending test-results & $20 \%$ \\
Tensile test & $\begin{array}{l}30 \% \\
\text { G3I }\end{array}$ & $\begin{array}{l}\text { Generic information } \\
\text { about the test } \\
\text { Description of the } \\
\text { experimental test }\end{array}$ & $20 \%$ \\
a32 & $\begin{array}{l}\text { Relevant experimental } \\
\text { parameters }\end{array}$ & $20 \%$ \\
a33 & Testing results & $40 \%$ \\
\hline
\end{tabular}

Criterion for the evaluation of the reports: Other components

Table 8. Criterion for the evaluation of the report: Component $b$.

\begin{tabular}{|c|c|c|c|}
\hline Criterion & Criterion (level 2) & & \\
\hline \multirow[t]{4}{*}{$b$} & $\begin{array}{l}\text { Global presentation of } \\
\text { the report }\end{array}$ & $15 \%$ & \\
\hline & bl & Graphic quality & $33.33 \%$ \\
\hline & b2 & Portuguese spelling & $33.33 \%$ \\
\hline & b3 & $\begin{array}{l}\text { Illustrations and elucidative } \\
\text { schemes }\end{array}$ & $33.33 \%$ \\
\hline
\end{tabular}

Table 9. Criterion for the evaluation of the report: Component c.

\begin{tabular}{|c|c|c|c|}
\hline Criterion & Criterion (level 2) & & \\
\hline \multirow[t]{5}{*}{ c } & Technical drawings & $10 \%$ & \\
\hline & $\mathrm{cl}$ & Dimensioning & 50 \\
\hline & $c 2$ & Representation of the glued surfaces & 10 \\
\hline & c3 & Correct representation of the lines & 30 \\
\hline & c4 & $\begin{array}{l}\text { Representation of the break along } \\
\text { the length, or a }\end{array}$ & 10 \\
\hline
\end{tabular}

${ }^{\text {a }}$ Representation in such a scale that makes possible to represent the object correctly without break. 
Table 10. Criterion for the evaluation of the report: Component e.

\begin{tabular}{llll}
\hline Criterion & Criterion (level 2) & & \\
\hline e & $\begin{array}{l}\text { Calculations and } \\
\text { dimensioning }\end{array}$ & $25 \%$ & $15 \%$ \\
el & Transverse load diagrams & $10 \%$ \\
e2 & Calculations of the reaction on the supports & $10 \%$ \\
e3 & Calculation of transverse loads & $10 \%$ \\
e4 & Calculation on the bending moment & $15 \%$ \\
e5 & Calculation of the inertia moment & $15 \%$ \\
e6 & Prediction of $P$ by calculating using the elastic & \\
& curve equation & $15 \%$ \\
e7 & Calculation of the bending stresses & $10 \%$ \\
& Application of a resistance dimensioning criterion & (can be the maximum normal stress) & \\
\end{tabular}

